Acute hemorrhage from the upper gastrointestinal tract is among the most frequently encountered emergency situations in gastroenterology. The most frequent causes of hemorrhage are complications due to peptic ulcer disease [1]. In rare cases, abundant hemorrhage is caused by Mallory-Weiss tears [2-4].

A 54-year-old man was admitted to our institution for hemorrhage from the upper gastrointestinal tract, which manifested with repeated retching and vomiting, followed by hematemesis, at $11.15 \mathrm{a} . \mathrm{m}$. He mentioned heavy alcohol abuse the day before. The initial clinical examination confirmed hemorrhagic shock, Riva-Rocci $70 / 40 \mathrm{mmHg}$, pulse $120 / \mathrm{min}$. The hemogram showed marked anemia, with erythrocyte values of $1.93 \times 10^{12} / 1$ and hemoglobin values of $63 \mathrm{~g} / \mathrm{l}$. After initial hemodynamic stabilization of the patient in the intensive-care unit (ICU), emergency endoscopy was performed at 12.00 a.m., and a MalloryWeiss tear measuring approximately $20 \times 4 \mathrm{~mm}$ was detected at the gastroesophageal junction (Figure 1). Endoscopic hemostasis was carried out with $4 \mathrm{ml}$ of diluted epinephrine $(1: 10000)$. After hemostasis and washing, no signs of bleeding from the lesion were observed. During treatment in the ICU, the patient

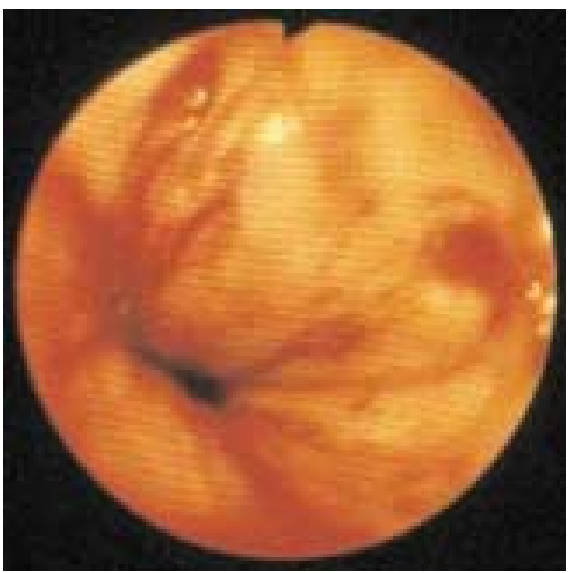

Figure 1 Mallory-Weiss tear, measuring approximately $20 \times 4 \mathrm{~mm}$, visualized at the esophagogastric junction during emergency endoscopy. was receiving intravenous fluids and transfusions. At 1.40 p.m., he began violent retching and vomiting fresh blood clots. Five minutes later, respiratory arrest and electromechanic dissociation developed. Cardiopulmonary resuscitation was unsuccessful, the patient died at 2.40 p.m. A giant Mallory-Weiss tear measuring $55 \times 5 \mathrm{~mm}$ and several smaller tears in the gastric fundus were found at autopsy. A vessel with a diameter of $2 \mathrm{~mm}$ was found in the lesion - probably the left gastric artery or one of its branches (Figure $\mathbf{2}$ ).

Mallory-Weiss tear is a mucosal laceration of the gastric cardia or gastroesophageal junction induced by retching or vomiting, which was first described by Kenneth Mallory and Soma Weiss in 1929 [5]. The lesion is generally believed to result from transient large gradients between intragastric and intrathoracic pressures at the gastroesophageal junction. When the gastroesophageal junction is elevated above the diaphragm, this gradient results in dilatation of the junction

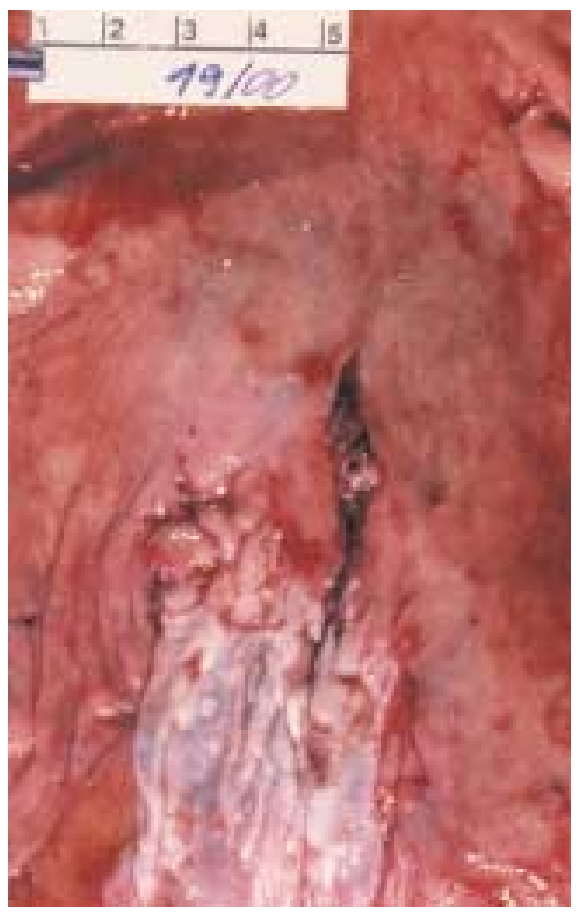

Figure 2 Giant laceration, measuring $55 \times 5 \mathrm{~mm}$, with a vessel stump, probably the left gastric artery, observed at autopsy. and thus in tears. Hiatal hernia appears to be a predisposing factor. The lesion accounts for $5-15 \%$ of cases of upper gastrointestinal bleeding and is usually single (80-90\%); two or three tears are seen in $10 \%$ and $7 \%$ of cases, respectively, and cases with more than three tears are extremely rare $[3,4]$. About $10 \%$ of the tears extend into the esophagus, but the lesion usually does not involve the esophagus alone. In one series, the average length of the tear was $2.1 \mathrm{~cm}$ [3]. In the patient described here, the giant tear resulted in exsanguination from a large vessel, probably the left gastric artery.

\section{P. Skok}

Dept. of Gastroenterology and Endoscopy, Maribor General Hospital, Maribor,

Slovenia

\section{References}

${ }^{1}$ Skok P. The epidemiology of hemorrhage from the upper gastrointestinal tract in the mid-nineties: has anything changed? Hepatogastroenterology 1998; 45: 2228 - 2233

2 Bubrick MP, Lundeen JW, Onstad GR et al. Mallory-Weiss tear: analysis of fiftynine cases. Surgery 1980; 88: 400-405

${ }^{3}$ Sugawa C, Benishek D, Walt AJ. Mallory-Weiss syndrome. Am J Surg 1983; 145: $30-33$

${ }^{4}$ Katz PO, Salas L. Less frequent causes of upper gastrointestinal bleeding. Gastroenterol Clin North Am 1993; 22: $875-889$

${ }^{5}$ Mallory GK, Weiss S. Hemorrhages from lacerations of the cardiac orifice of the stomach due to vomiting. Am J Med Sci 1929; 178: $506-515$

\section{Corresponding Author}

\section{P. Skok, M.D., Ph.D.}

Dept. of Gastroenterology and Endoscopy Maribor Internal Medicine Clinic Ljubljanska 5, 2000 Maribor, Slovenia Fax: $\quad+386-2-3312393$

E-mail: Pavel.Skok@sb-mb.si 